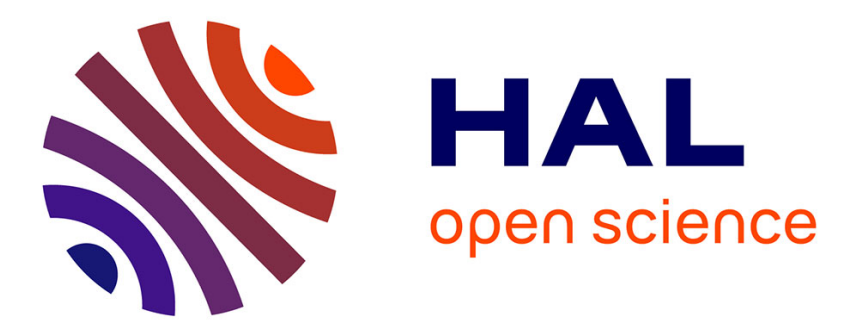

\title{
Segmentation of the Main Himalayan Thrust illuminated by Bayesian inference of interseismic coupling
}

\author{
Luca Dal Zilio, Romain Jolivet, Ylona van Dinther
}

\section{To cite this version:}

Luca Dal Zilio, Romain Jolivet, Ylona van Dinther. Segmentation of the Main Himalayan Thrust illuminated by Bayesian inference of interseismic coupling. Geophysical Research Letters, 2020, 47 (4), pp.e2019GL086424. 10.1029/2019GL086424 . hal-02485458

\section{HAL Id: hal-02485458 https://hal-ens.archives-ouvertes.fr/hal-02485458}

Submitted on 20 Feb 2020

HAL is a multi-disciplinary open access archive for the deposit and dissemination of scientific research documents, whether they are published or not. The documents may come from teaching and research institutions in France or abroad, or from public or private research centers.
L'archive ouverte pluridisciplinaire HAL, est destinée au dépôt et à la diffusion de documents scientifiques de niveau recherche, publiés ou non, émanant des établissements d'enseignement et de recherche français ou étrangers, des laboratoires publics ou privés. 


\title{
Segmentation of the Main Himalayan Thrust illuminated by Bayesian inference of interseismic coupling
}

\author{
Luca Dal Zilio ${ }^{1,2 *}$, Romain Jolivet ${ }^{3,4}$, Ylona van Dinther ${ }^{1,5}$ \\ ${ }^{1}$ Department of Earth Sciences, ETH Zürich, Sonneggstrasse 5, 8092 Zürich, Switzerland \\ 2 Seismological Laboratory, California Institute of Technology, Pasadena, California \\ ${ }^{3}$ Laboratoire de Géologie, Département de Géosciences, Ecole Normale Supérieure, \\ PSL Université, UMR 8538, Paris, France \\ ${ }^{4}$ Institut Universitaire de France, 1 rue Descartes, 75005 Paris, France \\ ${ }^{5}$ Department of Earth Sciences, Utrecht University, The Netherlands
}

\section{Key Points:}

- We propose a probabilistic interseismic coupling model of the Main Himalayan Thrust

- Our Bayesian analysis suggests heterogeneous coupling along the Main Himalayan Thrust

- Spatial coincidence between low coupling regions and subsurface ridges suggests a possible segmentation of the Main Himalayan Thrust

\footnotetext{
* Corresponding author: Luca Dal Zilio, dalzilio@caltech.edu
} 


\begin{abstract}
We use a recent compilation of geodetic data of surface displacements in a fully Bayesian approach to derive a probabilistic estimate of interseismic coupling along the Main Himalayan Thrust (MHT). Our probabilistic estimate of interseismic coupling highlights four large, highly-coupled patches separated by three potential barriers of low coupling. Locked patches overlap with estimated rupture areas of historical large earthquakes over the past centuries. The coincident spatial variability in coupling, seismicity, and prominent active topography, suggests a structural segmentation of the MHT imposed by inherited tectonic structures from the India-Eurasia collision. This correlation implies that inherited tectonic structures may affect how stress builds up along the MHT, thereby influencing the location and size of large Himalayan earthquakes and the growth of the mountain range.
\end{abstract}

\title{
Plain Language Summary
}

Large Himalayan earthquakes occur along the plate interface between the Indian and Eurasian plates: the Main Himalayan Thrust. Structural complexities of the downgoing Indian plate are thought to play a role in the segmentation of this large fault and hence its seismic potential. However, it is not clear how these tectonic structures affect the interseismic stress buildup between earthquakes. With geodetic data and a fully Bayesian approach, we estimate the pattern of interseismic coupling along the Main Himalayan Thrust, defined as a measure of kinematic locking along fault interfaces. We observe a heterogeneous distribution of interseismic coupling that coincides with the pattern of large earthquakes, topography, and subsurface ridges inherited from the India-Eurasia collision. These findings help us to highlight where large Himalayan earthquakes are more likely to occur.

\section{Introduction}

The magnitude $\left(\mathrm{M}_{\mathrm{w}}\right) 7.8$ Gorkha-Nepal earthquake of 2015 was a dramatic reminder of the importance of understanding seismic hazard in the Himalayas (e.g., Bilham et al., 2001) (Fig. 1). This densely populated region has been struck by some of the largest continental earthquakes, including the $1905 \mathrm{M}_{\mathrm{w}} 7.8$ Kangra earthquake, and the $2005 \mathrm{M}_{\mathrm{w}} 7.6$ Kashmir earthquake. It is also known to have produced larger historical earthquakes of magnitude larger than 8, such as the $1950 \mathrm{M}_{\mathrm{w}} 8.5$ Assam earthquake and the $1934 \mathrm{M}_{\mathrm{w}}$ 8.2 Nepal-Bihar earthquake (Chen and Molnar, 1990; Sapkota et al., 2013).

Tectonic shortening imposed by plate motion on interseismically locked, seismogenic faults leads to elastic strain accumulation, which is ultimately released by earthquakes (e.g., Savage, 1983). Geodetic observations allow derivation of spatial variations of strain rates induced by interseismic locking of the main boundary faults. Interseismic locking varies spatially along plate boundary faults, highlighting segments that are locked versus those that slip aseismically (e.g., Avouac, 2015). In the Himalayas, most large earthquakes have ruptured the Main Himalayan Thrust (MHT), 
the main plate boundary fault between the Indian and Eurasian plates (e.g., Bilham et al., 2001). Interseismic strain results from relative plate motion across the MHT, which seems to increase eastwards from $\sim 13 \pm 1.7 \mathrm{~mm} \mathrm{yr}^{-1}$ to $\sim 21 \pm 2.0 \mathrm{~mm} \mathrm{yr}^{-1}$ across the Himalayas (Stevens and Avouac, 2015).

There is now a relatively good coverage of Global Positioning System (GPS) stations (Kreemer et al., 2014), which allows quantification of the degree of fault locking and its spatial distribution on the MHT. For the purposes of this study, fault locking is referred to as coupling, defined as the ratio of the deficit of slip rate in the interseismic period divided by the long-term slip rate imposed by tectonic shortening. This ratio varies from 0 for a portion of the MHT that slips aseismically at a rate equal to the plate convergence rate to 1 for a fully locked fault. Many models derived from geodetic data suggest that interseismic coupling on subduction megathrusts worldwide is spatially heterogeneous, defining locked patches where stress increases more rapidly surrounded by segments that slip aseismically (e.g., Chlieh et al., 2008; Moreno et al., 2011). Megathrust earthquakes occur to first order on these interseismically locked patches (e.g., Loveless and Meade, 2011). Conversely, previously published models in the Himalayan region suggest that the MHT is nearly uniformly locked from the surface to beneath the front of the high range over a width of $100 \pm 20 \mathrm{~km}$ (Ader et al., 2012; Li et al., 2018; Ponraj et al., 2010; Sreejith et al., 2018; Stevens and Avouac, 2015; Yadav et al., 2019). Therefore, the MHT appears to be an anomaly with respect to subduction megathrusts worldwide. However, a recent and detailed GPS velocity solution over Bhutan highlights local variations in coupling, with a less wide fully coupled segment in eastern Bhutan and a partially unlocked deeper crustal ramp (Marechal et al., 2016).

Mapping the spatial distribution of interseismic coupling is key to understanding the segmentation of the MHT and its seismic potential (e.g., Stevens and Avouac, 2016). In addition, quantitative assessments of uncertainties on the slip deficit inferred from geodetic data are still missing. Here, we use a Bayesian approach to derive a probabilistic estimate of fault coupling along the MHT. Such probabilistic estimate does not rely on any spatial smoothing, an approach often used to regularize slip inversions. Contrarily to more classic, regularized slip and coupling inversion techniques, our approach explores all the possible distributions of coupling along the fault that explains the data. In doing so, we avoid explicit formulation of arbitrary constraints that restrict the range of possible models. Furthermore, we provide full posterior probability distributions of coupling made of the ensemble of plausible models that fit the observations and are consistent with prior constraints. 


\section{Methods}

\section{Geodetic Observations}

To assess the extent of interseismic coupling, we use an updated set of GPSderived velocities spanning the 1990s to 2015 (Kreemer et al., 2014). This dataset was recently used to estimate the width of coupling across the MHT through a series of two-dimensional transects (Lindsey et al., 2018) (Fig. S1). To better resolve the pattern of coupling we also include levelling measurements from the Survey of Nepal collected between 1977 and 1990 (Jackson and Bilham, 1994).

Our fault model considers the total length of the arc over roughly $2000 \mathrm{~km}$ (Stevens and Avouac, 2015), from $73^{\circ} \mathrm{E}$ to $96^{\circ} \mathrm{E}$ (Fig. S1). The dip angle is set to $10^{\circ}$ as in previous studies (Ader et al., 2012; Stevens and Avouac, 2015). To account for the arcuate and irregular shape of the MHT, we divide the fault geometry into four planar sub-fault blocks. These sub-faults are discretized in 353 triangles with variable size, smaller near the surface $(\sim 45-50 \mathrm{~km})$ and larger down-dip $(\sim 250 \mathrm{~km})$. As estimates of the extent of plate coupling depend on the direction and rate of the plate convergence, we set a specific convergence rate and azimuth for each sub-fault based on plate motion models and regional geodetic measurements (see Table S1). We also assume that the otherwise rigidly moving Indian plate is fragmenting around the eastern end of the Himalayan arc where there is evidence for internal deformation (Vernant et al., 2014). To account for this deformation, we consider two distinct blocks and related subnetworks: Indian and the Shillong block south of the eastern Himalaya (Fig. S1). The elastostatic Green's functions of each sub-fault and block, relating unit slip on each patch to surface displacements at the data locations, are thus computed assuming a different long-term convergence rate and azimuth. The inversion solves for the poles of rotation with respect to India, as well as the coupling pattern. We predict the response to subsurface fault slip at each data (GPS and levelling) location assuming a stratified semi-infinite elastic medium (Simons et al., 2002; Zhu and Rivera, 2002). Our elastic half-space consists of 3 layers with elastic properties following the average properties of the crust in the region (Pandey et al., 1995) (Fig. S2).

\section{Bayesian analysis}

We consider the forward problem $\mathbf{d}=\mathbf{G m}$, where $\mathbf{d}$ is the vector containing the horizontal component of the GPS-derived velocities and of the vertical displacement of the levelling-derived measurements, $\mathbf{m}$ is the vector of model parameters, and $\mathbf{G}$ is the matrix of Green's functions. Green's functions consist of surface displacement of each data location (GPS and levelling) for unit slip on each point of the fault. G includes elements of reference frame estimate for the GPS displacement field as well. We solve the inverse problem to infer the distribution of model parameters $(\mathbf{m})$ consistent with our data (d). The solution to this inverse problem is non-unique and large uncertainties on the parameters are expected. Therefore, instead of deriving a single model, we explore all potential solutions using a Bayesian approach to derive 
the posterior probability density function (PDF) of our model given our set of data, $\mathbf{p}(\mathbf{m} \mid \mathbf{d})$ (Minson et al., 2013). We thus derive a probabilistic estimate of the degree of fault locking along the MHT. Following Bayes's theorem, we write the posterior PDF as:

$$
\mathbf{p}(\mathbf{m} \mid \mathbf{d}) \propto p(\mathbf{m}) \exp \left[-\frac{1}{2}(\mathbf{d}-\mathbf{G m})^{T} \mathbf{C}_{\chi}^{-1}(\mathbf{d}-\mathbf{G m})\right]
$$

where $\mathbf{p}(\mathbf{m})$ is the prior PDF of the model that describes our state of knowledge before acquiring data, $\mathbf{d}$ is the data vector, $\mathbf{G}$ the Green's functions matrix, and $\mathbf{m}$ is the vector of model parameters. $\mathbf{C}_{\chi}$ is the covariance matrix in the data space, defined as the sum of the data covariance matrix $\mathbf{C}_{\mathbf{d}}$, (i.e., measurement error matrix) and the prediction error matrix, $\mathbf{C}_{\mathbf{p}}$, which describes uncertainties in our elastic model for the crust:

$$
\mathbf{C}_{\chi}=\mathbf{C}_{\mathbf{d}}+\mathbf{C}_{\mathbf{p}}
$$

We account for prediction uncertainties (i.e., in the $\mathbf{C}_{\mathbf{p}}$ covariance matrix) due to inaccuracies in this layered elastic model using the approach of Duputel et al. (2014). The uncertainty on the elastic structure, presented as grey standard deviation in Fig. S2, is estimated by comparing previously published models across the entire Himalayan region. We need a careful description of errors in order to not overfit the data and produce reasonable estimates of coupling uncertainties on each portion of the megathrust. Considering the variability and uncertainties on the $1 \mathrm{D}$ velocity models (Fig. S2), we test both $5 \%$ and $10 \%$ uncertainty on the elastic properties of each layer of the elastic half-space. We prescribed $10 \%$ uncertainty in the reference model. Previous studies have shown that not including the prediction errors when sampling for posterior PDF of coupling may lead to biased results (Jolivet et al., 2015).

The solution of the inverse problem is the posterior ensemble of all plausible interseismic coupling models $(\mathbf{m})$ that fit the GPS data $(\mathbf{d})$ and that are consistent with our prior hypotheses. We test two different prior hypothesis: (1) a uniform PDF assuming no prior knowledge on the model parameters and (2) a binary prior (with $10 \%$ uncertainties) along-dip — that is, imposing a prior of 1 from the surface to $100 \mathrm{~km}$ downdip (18 km depth), followed by a linear decrease between 100 and 110 $\mathrm{km}(18-20 \mathrm{~km}$ depth$)$, and a constant prior of 0 at depth $>20 \mathrm{~km}$. We generate 360 '000 models corresponding to the posterior information on geodetic coupling given measured interseismic velocities. Our final solution consists of an ensemble of models that are statistically distributed according to the posterior PDF.

\section{Interseismic coupling distribution}

The posterior mean coupling model shows remarkable spatial variations in interseismic coupling, both down-dip and along-strike the MHT (Fig. 2a). We infer discrete highly-coupled segments along the fault extending throughout the arc. Coupling is high at the front, where the Main Frontal Thrust (MFT) - the youngest and southernmost thrust of the Himalayan wedge - reaches the surface and the resolu- 
tion resulting from observations is highest. Down-dip, coupling tapers to negligible values around 100-120 km north from the MFT. From west to east, we observe a large lateral variability in geodetic coupling. Four large (ca. 300-450 km) and discrete highly-coupled segments $(>0.8)$ are separated by three relatively smaller $(c a .100 \mathrm{~km})$ regions with lower coupling $(<0.3)$. These lateral variations of coupling raise two fundamental questions. First, are these variations a robust feature driven by the data? Second, what difference between our approach and previously published methods leads to the emergence of these low coupling segments along the MHT?

We interrogate the posterior PDF of coupling to assess the robustness of our estimate by considering six representative local PDFs of coupling (nodes 1-6 in Fig. 2a). Marginal PDFs for nodes 2, 4, and 6 show a $>75 \%$ probability that fault coupling exceeds 0.8 . On the other hand, for node 1 and 5 , we infer a $68 \%$ probability that fault coupling is lower than 0.4 , confirming a significantly higher probability of low coupling. In contrast, the shape of the cumulative distribution function of coupling on node 3 suggests a wider range of probable values, not far from the initial prior distributions (i.e., uniform probability of coupling) but still tending towards lower values of coupling. This similarity of prior and posterior distributions suggests the data are less informative to derive fault coupling along this limited section of the model. Although our inversions include larger covariances compared to previous studies (Ader et al., 2012; Stevens and Avouac, 2015), observed vs. predicted horizontal GPS displacements (Fig. 2b) and residuals (Fig. S3) from our mean model show a good agreement with the geodetic measurements. However, it is important to note that the regions with low coupling are spatially coincident with the block boundaries, and where the GPS data are less dense (Fig. S1). To check the reliability of our results, we perform two tests in which we assume $(i)$ a fault model with a constant convergence rate $\left(17 \pm 3 \mathrm{~mm} \mathrm{yr}^{-1}\right)$ and azimuth $\left(8^{\circ} \mathrm{E}\right)$, and $(i i) 5 \%$ uncertainty on the elastic properties of each layer of the elastic half-space. Despite small variations, these fault models show very similar results as the regions with low coupling are still easily detectable (Fig. S4 and S5). These results thus provide strong evidence that the inferred variations of interseismic coupling are consistent with the data and the given posterior uncertainties.

For comparison, instead of assuming a uniform non-informative prior, we consider a constrained prior PDF distribution. In particular, we assume that the MHT is highly-coupled from the surface to $18-\mathrm{km}$-depth and with negligible coupling at depths greater than $20 \mathrm{~km}$. To do so, we consider a tight Gaussian prior PDF with a standard deviation of $10 \%$, centered on 1 from the surface to 18 -km-depth (i.e., fully locked) and on 0 for depths greater than $20 \mathrm{~km}$ (i.e., slip at plate convergence rate). All other assumptions and hypothesis are kept identical to our reference model. This strong assumption is based on previous geodetic studies using GPS campaign and levelling measurements (Bollinger et al., 2004), a few continuous GPS stations (Bettinelli et al., 2006), and a recent physics-based forward model of the Himalayan seismic cycle (Dal Zilio et al., 2019). Also, the location of the down-dip end of the locked fault zone is consistent with the seismicity pattern observed in Nepal Himalaya (Cattin and 
Avouac, 2000), and the postseismic deformation following the $2015 \mathrm{M}_{\mathrm{w}} 7.8$ Gorkha earthquake (Gualandi et al., 2017).

The posterior mean model suggests the MHT is highly-coupled from its surface expression along the Himalayan foothills to beneath the front of the high range about $100 \mathrm{~km}$ to the north (Fig. S6). In general, coupling is nearly binary (1-to-0), with a sharp transition between the coupled and creeping zones, similarly to what has been observed in previous studies (Ader et al., 2012; Stevens and Avouac, 2015). This distribution of coupling is actually very close to the prior PDF we have considered. Strikingly, residuals are of the same order of magnitude as in our reference model with uniform prior. This leads to the conclusion that both models, the one assuming a constrained prior and the one with a uniform prior, fit the data almost equally well and are both possible. However, examination of marginal posterior PDFs suggest that the model derived from highly-constrained prior is only a subset of potential models. As shown by marginal PDFs of coupling on node 1, 3, and 5 (Fig. S6), models with high coupling are not excluded, but they are less probable than low coupled models given the available data. Homogeneous coupling along the MHT thus results mainly from a strong prior assumption. On the other hand, relaxing this hypothesis reveals a complex distribution of coupling and this complex distribution is more probable given the available data as shown by the posterior uncertainties directly translated from the data.

\section{Segmentation of the Himalayan megathrust and seismicity}

The spatial variability of interseismic coupling is an important factor to consider in interpreting relationships with the slip distribution of historical ruptures (Fig. 3). Along-strike, low coupling regions around nodes 1, 3, and 5 (Fig. 2a) coincide with three subsurface Indian basement ridges in the Indo-Gangetic plains: The Delhi-Haridwar ridge (DHR), the Faizabad ridge (FR), and the Munger-Saharsa ridge (MSR). These subsurface basement ridges extend northward across the Himalayan foothills and they might have affected the development of the arcuate shape and the morphology of the Himalayan arc. They have been detected first from basin thickness changes (Raiverman et al., 1983), and they have been confirmed by the analysis of arc-parallel gravity anomalies (Hetényi et al., 2016). They typically include oblique to transverse synclines, folds, fracture zones and/or strike-slip faults oriented transverse to the strike of the Himalaya, which are associated with normal faulting and strike-slip seismicity (Cannon et al., 2018; Murphy et al., 2014). Details of the origin and nature of the lineaments, however, remain mostly obscure at present.

The subduction of these major tectonic structures may relate to a segmentation in the seismic behavior of the MHT. Despite significant uncertainties, the rupture extent of major and great Himalayan earthquakes for past two hundred years appears to correlate with the regions of ridge subduction and the pattern of coupling (Fig. 3b). For example, the eastern edge of the 1905 Kangra earthquake rupture appears 
to approximately coincide with the Delhi-Hardwar ridge (Gahalaut and Kundu, 2012; Wallace et al., 2005). The western edge of the 1803 rupture, though not well constrained, abuts the Delhi-Hardwar ridge (Rajendran and Rajendran, 2005). The 1934 Nepal Bihar earthquake rupture propagated eastward until or into the Munger-Saharsa ridge (Hough and Bilham, 2008). However, it should be noted that an error of about $50 \mathrm{~km}$ could exist in the estimation of the rupture extent and rupture dimensions, and in the northward extrapolation of the ridges under the Himalayan region (Gahalaut and Kundu, 2012).

Recorded $\mathrm{M} \geq 4.5$ earthquakes (NEIC catalog from 1964 to 2018) show that the background crustal seismicity varies along-strike (Fig. 3c). Cumulative seismic moment released reveals along-strike variations with less seismic moment released in the three regions corresponding to the subsurface ridges. In particular, the cumulative effect of all smaller events does not reach that of a single M6 event. Furthermore, low seismicity across the Faizabad ridge has been evidenced by a dense seismic network in Nepal (Ader et al., 2012). Relocated microseismic activity (Ader et al., 2012; Mahesh et al., 2013), which extends over two regions from $77^{\circ} \mathrm{E}$ and $81^{\circ} \mathrm{E}$ and from $81^{\circ} \mathrm{E}$ to $87^{\circ} \mathrm{E}$, respectively, follow the down-dip edge of the highly-coupled patches quite well (Fig. S7). East of Bhutan, in Arunachal Pradesh, there is a seismically active band that extends into the orogen. Also, the cluster of seismicity extending into the Himalayan orogen at $77.5-78^{\circ} \mathrm{E}$ turns northward as a possible continuation of the Delhi-Haridwar ridge.

\section{Coupling vs. topography}

If interseismic coupling is stable over geological time scales (Kyr), the resulting pattern of strain should influence the construction of topography locally. To first order, topography contour lines show how the Himalaya rise abruptly at a distance of about 120-150 km from the Main Frontal Thrust (Fig. 4a). Notably, the down-dip end of the highly-coupled section of the MHT is spatially coincident with the abrupt rise in topography. Such correlation could reflect anelastic strain, which contributes to topographic uplift in the long run (Bilham et al., 1997; Stevens and Avouac, 2015). Such anelastic deformation suggests that the down-dip limit of the brittle-ductile transition is located where the shear stress accumulation is the highest, and drops under topography greater than $3500 \mathrm{~m}$ of elevation (Bollinger et al., 2004).

It is also interesting to notice that the largest across-strike graben of the Himalayan belt, the Kaurik-Chango Rifts, the Thakola Rifts and the Yadong Rifts, lie near the prolongation of the three ridges (Fig. 4a). In particular, normal faulting earthquakes continuously occur along N-S fault planes in the Kaurik-Chango Rift (Gahalaut and Arora, 2012), where the eastern limit of the 1905 Kangra earthquake is located. Possibly, the Kaurik-Chango Rift keeps this part of the Himalayan seismic belt in a dilated (or low stress) state so that earthquake ruptures along the MHT do not extend through it. It should be noted, however, that the assumption of a linear 
extension in the trend of these ridges below the Himalaya is uncertain and that the ridges may in fact deviate from their extrapolated linear trend.

A link between topography and coupling suggests a long-term influence of the seismic behavior of the megathrust and topography building. One possibility to reconcile the segmentation of topography and that of coupling is to consider the topographic effects of ridge subduction. In subduction zones, seafloor observations (Singh et al., 2011) and numerical experiments (Ruh et al., 2016) suggest that subduction of large topographic structures (e.g., seamounts) result in a bulge above the underthrusting seamount and normal faults within the overriding plate. If this holds for the Himalayan orogen, the long-term passage of these three basement ridges could explain the topography cusps and the arc-perpendicular normal faults. More generally, the correlation between the pattern of interseismic coupling and the topography suggests that segmentation and effective frictional properties vary little in time, while irrecoverable strain of the Himalayan wedge is small during the interseismic period. As previously inferred from the colocation of the bulge of interseismic uplift with the front of the Higher Himalaya (Meade, 2010), some fraction of the interseismic geodetic strain, albeit small as discussed above, could be actually anelastic and contributes to topographic uplift over geological time scales.

To investigate lateral variations in collisional structure we also compare (i) the Arc-Parallel Topography Anomalies (APTA) (Hetényi et al., 2016), which define the topography differences from the average arc-perpendicular profile, (ii) the 0.5 contour line of coupling, and (iii) the location of the three subsurface ridges (Fig 4b). The variation of the APTA exceed $500 \mathrm{~m}$ with a number of alternating negative and positive patches throughout the arc. Neglecting important effects of climate conditions and surface processes (e.g., Whipple, 2009), the higher values at the front of the range are located where the coupling is low and the three subsurface ridges come across the Main Frontal Thrust. The western boundary near $76.5^{\circ} \mathrm{E}$, aligned with the DelhiHaridwar ridge (DHR), is visible in the topography anomalies. The middle boundary near $82.5^{\circ} \mathrm{E}$, aligned with the Faizabad ridge (FR), as well as the eastern end of the Munger-Saharsa ridge (MSR) near $87.5^{\circ} \mathrm{E}$, are also visible in the topography anomalies. This latter is certainly a major boundary in (or of) the Indian plate (Hetényi et al., 2016). Despite some exceptions (e.g., between 89 and $92^{\circ} \mathrm{E}$ ), the correlation between the topography anomalies and coupling suggests that fault segments beneath positive APTA are likely more aseismic, as already observed in subduction zones (Song and Simons, 2003).

\section{Conclusions}

In summary, we propose that inherited structures along the Himalayan arc induce a zonation of interseismic coupling along the plate interface. Regardless of uncertainties, our probabilistic estimate of interseismic coupling along the MHT suggests that the Himalayan megathrust is segmented by regions of low coupling. These low- 
coupled patches overlap with inherited structures. Despite competing hypotheses, the segmentation of the orogen into these blocks is also visible in the along-strike rupture extension of historical earthquakes. Large earthquakes of the past millennium do not propagate across segment boundaries defined by lower plate inherited structure (Gahalaut and Arora, 2012; Hetényi et al., 2016). Therefore, the here identified low-coupled patches potentially set three boundaries for the lateral extent of future megathrust earthquakes. From a general agreement between previous results (Ader et al., 2012; Stevens and Avouac, 2015), geodetic data, and geological constraints, our results confirm that the fraction of anelastic deformation in the highly-coupled regions might be within uncertainties of the geodetic data $(\leq 10 \%)$. These new results highlight important targets for future studies, which will be essential to question how these segment boundaries control interseismic strain accumulation. Future GPS campaigns should assist in answering this challenging but crucial question.

\section{Acknowledgments}

Work for this article has received funding from the European Research Council (ERC) under the European Union's Horizon 2020 Research and Innovation Programme (Grant Agreement Number: 758210 - Geo4D). L.D.Z. was supported by the SNSF 2-77090-14 project Swiss-AlpArray SINERGIA and the Cecil and Sally Drinkward Postdoctoral Scholar at Caltech. We thank V.L. Stevens, J.-P. Avouac, G. Hetény, M. Simons, L. Bollinger, C. Pranger, A. Gualandi, K. Wang, and S. Michel for constructive comments and discussions. We are grateful to G. Hetény for providing us with GMT scripts to plot Fig. 1 and the Arc-Parallel Topography Anomalies (Hetényi et al., 2016). We thank the Editor and two anonymous reviewers for providing insightful comments that helped to improve the quality of this paper. Data related to this paper can be downloaded from the following link: https://doi.org/10.22002/d1.1317

\section{Author contributions}

L.D.Z. and R.J. conceived the research, designed the study, performed and analyzed the fault modeling, and wrote the manuscript. Y.v.D. commented on the analysis. All authors took part in finalizing the manuscript.

\section{References}

Ader, T., Avouac, J.-P., Liu-Zeng, J., Lyon-Caen, H., Bollinger, L., Galetzka, J., Genrich, J., Thomas, M., Chanard, K., Sapkota, S. N., et al. (2012). Convergence rate across the nepal himalaya and interseismic coupling on the main himalayan thrust: Implications for seismic hazard. Journal of Geophysical Research: Solid Earth (1978-2012), 117(B4). 
Avouac, J.-P. (2015). From geodetic imaging of seismic and aseismic fault slip to dynamic modeling of the seismic cycle. Annual Review of Earth and Planetary Sciences, 43:233-271.

Berthet, T., Ritz, J.-F., Ferry, M., Pelgay, P., Cattin, R., Drukpa, D., Braucher, R., and Hetényi, G. (2014). Active tectonics of the eastern himalaya: New constraints from the first tectonic geomorphology study in southern bhutan. Geology, 42(5):427-430.

Bettinelli, P., Avouac, J.-P., Flouzat, M., Jouanne, F., Bollinger, L., Willis, P., and Chitrakar, G. R. (2006). Plate motion of india and interseismic strain in the nepal himalaya from gps and doris measurements. Journal of Geodesy, 80(8-11):567-589.

Bilham, R. (2009). The seismic future of cities. Bulletin of Earthquake Engineering, $7(4): 839$.

Bilham, R. and England, P. (2001). Plateau 'pop-up'in the great 1897 assam earthquake. Nature, 410(6830):806.

Bilham, R., Gaur, V. K., and Molnar, P. (2001). Himalayan seismic hazard. Science, 293(5534):1442-1444.

Bilham, R., Larson, K., Freymueller, J., Jouanne, F., LeFort, P., Leturmy, P., Mugnier, J., Gamond, J., Glot, J., Martinod, J., et al. (1997). Gps measurements of present-day convergence across the nepal himalaya. Nature, 386(6620):61-64.

Bollinger, L., Avouac, J., Cattin, R., and Pandey, M. (2004). Stress buildup in the himalaya. Journal of Geophysical Research: Solid Earth (1978-2012), 109(B11).

Bollinger, L., Sapkota, S. N., Tapponnier, P., Klinger, Y., Rizza, M., Van Der Woerd, J., Tiwari, D., Pandey, R., Bitri, A., and Bes de Berc, S. (2014). Estimating the return times of great himalayan earthquakes in eastern nepal: Evidence from the patu and bardibas strands of the main frontal thrust. Journal of Geophysical Research: Solid Earth, 119(9):7123-7163.

Cannon, J., Murphy, M., and Taylor, M. (2018). Segmented strain accumulation in the high himalaya expressed in river channel steepness. Geosphere, 14(3):1131-1149.

Cattin, R. and Avouac, J. (2000). Modeling mountain building and the seismic cycle in the himalaya of nepal. Journal of Geophysical Research, 105(B6):13389-13407.

Chen, W.-P. and Molnar, P. (1990). Source parameters of earthquakes and intraplate deformation beneath the shillong plateau and the northern indoburman ranges. Journal of Geophysical Research: Solid Earth, 95(B8):12527-12552.

Chlieh, M., Avouac, J.-P., Sieh, K., Natawidjaja, D. H., and Galetzka, J. (2008).

Heterogeneous coupling of the sumatran megathrust constrained by geodetic and paleogeodetic measurements. Journal of Geophysical Research: Solid Earth, $113(\mathrm{~B} 5)$.

Ciesin, C. (2005). Gridded population of the world version 3 (gpwv3): population density grids. Palisades, NY: Socioeconomic Data and Applications Center (SEDAC), Columbia University.

Dal Zilio, L., van Dinther, Y., Gerya, T., and Avouac, J.-P. (2019). Bimodal seismicity in the himalaya controlled by fault friction and geometry. Nature communications, $10(1): 48$ 
Duputel, Z., Agram, P. S., Simons, M., Minson, S. E., and Beck, J. L. (2014). Accounting for prediction uncertainty when inferring subsurface fault slip. Geophysical Journal International, 197(1):464-482.

Gahalaut, V. and Arora, B. (2012). Segmentation of seismicity along the himalayan arc due to structural heterogeneities in the under-thrusting indian plate and overriding himalayan wedge. Episodes, 35(4):493-500.

Gahalaut, V. and Kundu, B. (2012). Possible influence of subducting ridges on the himalayan arc and on the ruptures of great and major himalayan earthquakes. Gondwana Research, 21(4):1080-1088.

Gualandi, A., Avouac, J.-P., Galetzka, J., Genrich, J. F., Blewitt, G., Adhikari, L. B., Koirala, B. P., Gupta, R., Upreti, B. N., Pratt-Sitaula, B., et al. (2017). Pre-and post-seismic deformation related to the 2015 , mw 7.8 gorkha earthquake, nepal. Tectonophysics, 714:90-106.

Hetényi, G., Cattin, R., Berthet, T., Le Moigne, N., Chophel, J., Lechmann, S., Hammer, P., Drukpa, D., Sapkota, S. N., Gautier, S., et al. (2016). Segmentation of the himalayas as revealed by arc-parallel gravity anomalies. Scientific reports, 6:33866.

Hough, S. E. and Bilham, R. (2008). Site response of the ganges basin inferred from re-evaluated macroseismic observations from the 1897 shillong, 1905 kangra, and 1934 nepal earthquakes. Journal of Earth System Science, 117(2):773-782.

Jackson, M. and Bilham, R. (1994). Constraints on himalayan deformation inferred from vertical velocity fields in nepal and tibet. Journal of Geophysical Research, 99:13-897.

Jolivet, R., Simons, M., Agram, P., Duputel, Z., and Shen, Z.-K. (2015). Aseismic slip and seismogenic coupling along the central san andreas fault. Geophysical Research Letters, 42(2):297-306.

Kreemer, C., Blewitt, G., and Klein, E. C. (2014). A geodetic plate motion and global strain rate model. Geochemistry, Geophysics, Geosystems, 15(10):3849-3889.

Kumar, S., Wesnousky, S. G., Jayangondaperumal, R., Nakata, T., Kumahara, Y., and Singh, V. (2010). Paleoseismological evidence of surface faulting along the northeastern himalayan front, india: Timing, size, and spatial extent of great earthquakes. Journal of Geophysical Research: Solid Earth, 115(B12).

Li, S., Wang, Q., Yang, S., Qiao, X., Nie, Z., Zou, R., Ding, K., He, P., and Chen, G. (2018). Geodetic imaging mega-thrust coupling beneath the himalaya. Tectonophysics, 747:225-238.

Lindsey, E. O., Almeida, R., Mallick, R., Hubbard, J., Bradley, K., Tsang, L. L., Liu, Y., Burgmann, R., and Hill, E. M. (2018). Structural control on down-dip locking extent of the himalayan megathrust. Journal of Geophysical Research: Solid Earth.

Loveless, J. P. and Meade, B. J. (2011). Spatial correlation of interseismic coupling and coseismic rupture extent of the $2011 \mathrm{mw}=9.0$ tohoku-oki earthquake. Geophysical Research Letters, 38(17).

Mahesh, P., Rai, S., Sivaram, K., Paul, A., Gupta, S., Sarma, R., and Gaur, V. (2013). One-dimensional reference velocity model and precise locations of earthquake hypocenters in the kumaon-garhwal himalaya. Bulletin of the Seismological Society 
of America, 103(1):328-339.

Marechal, A., Mazzotti, S., Cattin, R., Cazes, G., Vernant, P., Drukpa, D., Thinley, K., Tarayoun, A., Roux-Mallouf, L., Thapa, B. B., et al. (2016). Evidence of interseismic coupling variations along the bhutan himalayan arc from new gps data. Geophysical Research Letters, 43(24).

Meade, B. J. (2010). The signature of an unbalanced earthquake cycle in himalayan topography? Geology, 38(11):987-990.

Minson, S., Simons, M., and Beck, J. (2013). Bayesian inversion for finite fault earthquake source models i-theory and algorithm. Geophysical Journal International, 194(3):1701-1726.

Moreno, M., Melnick, D., Rosenau, M., Bolte, J., Klotz, J., Echtler, H., Baez, J., Bataille, K., Chen, J., Bevis, M., et al. (2011). Heterogeneous plate locking in the south-central chile subduction zone: Building up the next great earthquake. Earth and Planetary Science Letters, 305(3-4):413-424.

Murphy, M. A., Taylor, M. H., Gosse, J., Silver, C., Whipp, D., and Beaumont, C. (2014). Limit of strain partitioning in the himalaya marked by large earthquakes in western nepal. Nature Geoscience, 7(1):38.

Pandey, M., Tandukar, R., Avouac, J., Lave, J., and Massot, J. (1995). Interseismic strain accumulation on the himalayan crustal ramp (nepal). Geophysical Research Letters, $22(7): 751-754$.

Ponraj, M., Miura, S., Reddy, C., Prajapati, S., Amirtharaj, S., and Mahajan, S. (2010). Estimation of strain distribution using gps measurements in the kumaun region of lesser himalaya. Journal of Asian Earth Sciences, 39(6):658-667.

Raiverman, V., Kunte, S., Mukherjea, A., et al. (1983). Basin geometry, cenozoic sedimentation and hydrocarbon prospects in northwestern himalaya and indo-gangetic plains. Petroleum Asia Journal, 6(IV):67-92.

Rajendran, C. and Rajendran, K. (2005). The status of central seismic gap: a perspective based on the spatial and temporal aspects of the large himalayan earthquakes. Tectonophysics, 395(1-2):19-39.

Ruh, J. B., Sallarès, V., Ranero, C. R., and Gerya, T. (2016). Crustal deformation dynamics and stress evolution during seamount subduction: High-resolution 3-d numerical modeling. Journal of Geophysical Research: Solid Earth, 121(9):6880-6902.

Sapkota, S., Bollinger, L., Klinger, Y., Tapponnier, P., Gaudemer, Y., and Tiwari, D. (2013). Primary surface ruptures of the great himalayan earthquakes in 1934 and 1255. Nature Geoscience, 6(1):71-76.

Savage, J. (1983). A dislocation model of strain accumulation and release at a subduction zone. Journal of Geophysical Research: Solid Earth, 88(B6):4984-4996.

Simons, M., Fialko, Y., and Rivera, L. (2002). Coseismic deformation from the $1999 \mathrm{~m} \mathrm{w}$ 7.1 hector mine, california, earthquake as inferred from insar and gps observations. Bulletin of the Seismological Society of America, 92(4):1390-1402.

Singh, S. C., Hananto, N., Mukti, M., Robinson, D. P., Das, S., Chauhan, A., Carton, H., Gratacos, B., Midnet, S., Djajadihardja, Y., et al. (2011). Aseismic zone and 
earthquake segmentation associated with a deep subducted seamount in sumatra. Nature Geoscience, 4(5):308.

Song, T.-R. A. and Simons, M. (2003). Large trench-parallel gravity variations predict seismogenic behavior in subduction zones. Science, 301(5633):630-633.

Sreejith, K., Sunil, P., Agrawal, R., Saji, A. P., Rajawat, A., and Ramesh, D. (2018). Audit of stored strain energy and extent of future earthquake rupture in central himalaya. Scientific reports, 8(1):16697.

Stevens, V. and Avouac, J. (2015). Interseismic coupling on the main himalayan thrust. Geophysical Research Letters, 42(14):5828-5837.

Stevens, V. and Avouac, J.-P. (2016). Millenary mw $>9.0$ earthquakes required by geodetic strain in the himalaya. Geophysical Research Letters, 43(3):1118-1123.

Vernant, P., Bilham, R., Szeliga, W., Drupka, D., Kalita, S., Bhattacharyya, A., Gaur, V., Pelgay, P., Cattin, R., and Berthet, T. (2014). Clockwise rotation of the brahmaputra valley relative to india: Tectonic convergence in the eastern himalaya, naga hills, and shillong plateau. Journal of Geophysical Research: Solid Earth, 119(8):6558-6571.

Wallace, K., Bilham, R., Blume, F., Gaur, V., and Gahalaut, V. (2005). Surface deformation in the region of the 1905 kangra $m w=7.8$ earthquake in the period 1846-2001. Geophysical Research Letters, 32(15).

Whipple, K. X. (2009). The influence of climate on the tectonic evolution of mountain belts. Nature geoscience, 2(2):97.

Yadav, R. K., Gahalaut, V. K., Bansal, A. K., Sati, S., Catherine, J., Gautam, P., Kumar, K., and Rana, N. (2019). Strong seismic coupling underneath garhwal-kumaun region, nw himalaya, india. Earth and Planetary Science Letters, 506:8-14.

Zhu, L. and Rivera, L. A. (2002). A note on the dynamic and static displacements from a point source in multilayered media. Geophysical Journal International, 148(3):619-627. 


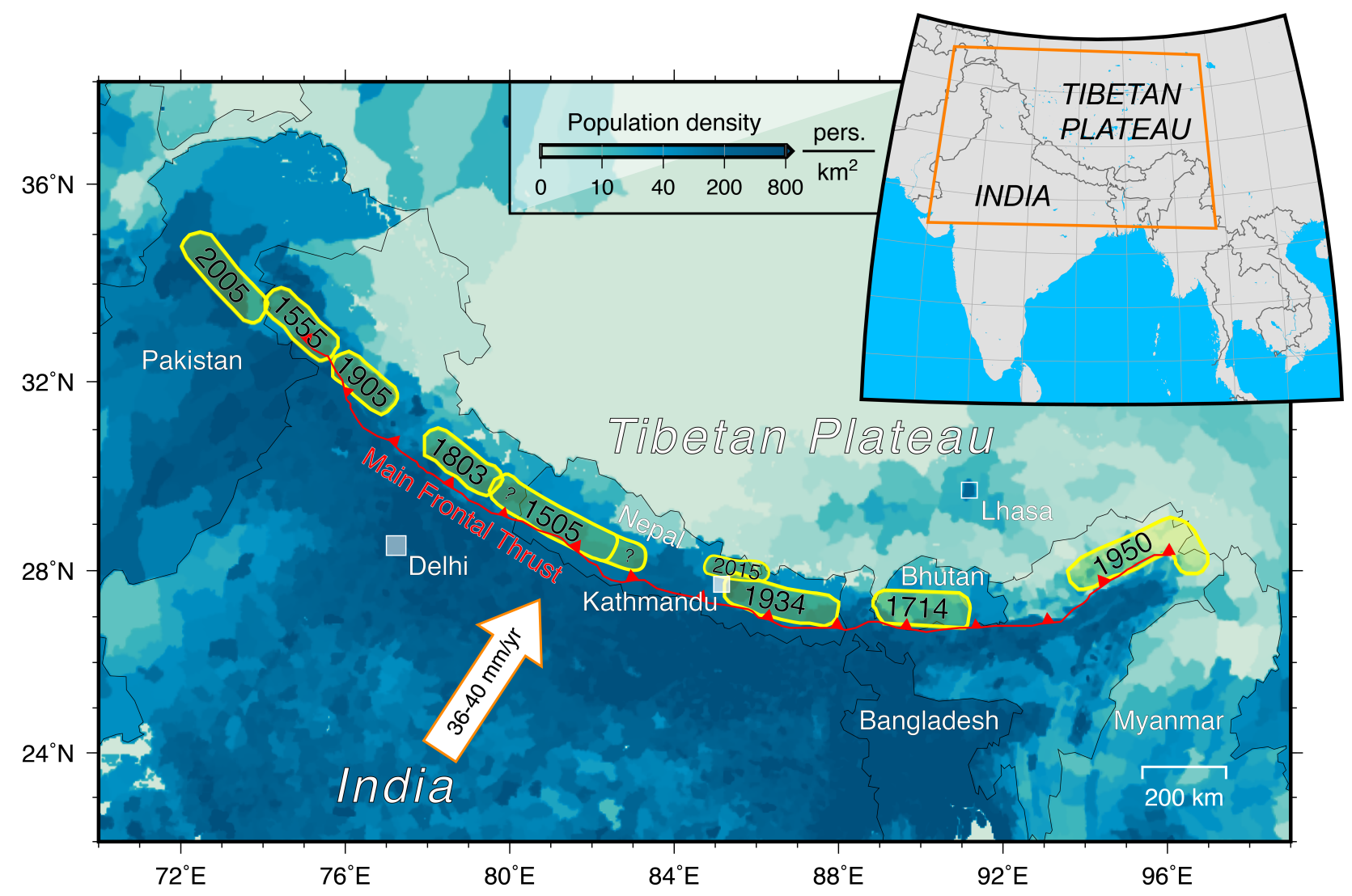

Figure 1. Great earthquakes in the Himalayas since 1500 A.D. Yellow rupture areas of magnitude $>7.5$ and larger events are schematic and represent the published along-arc extent estimates Berthet et al. (2014); Bilham (2009); Bilham and England (2001); Bollinger et al. (2014); Kumar et al. (2010). Background map shows the population density distribution Ciesin (2005). Inset locates main map. 


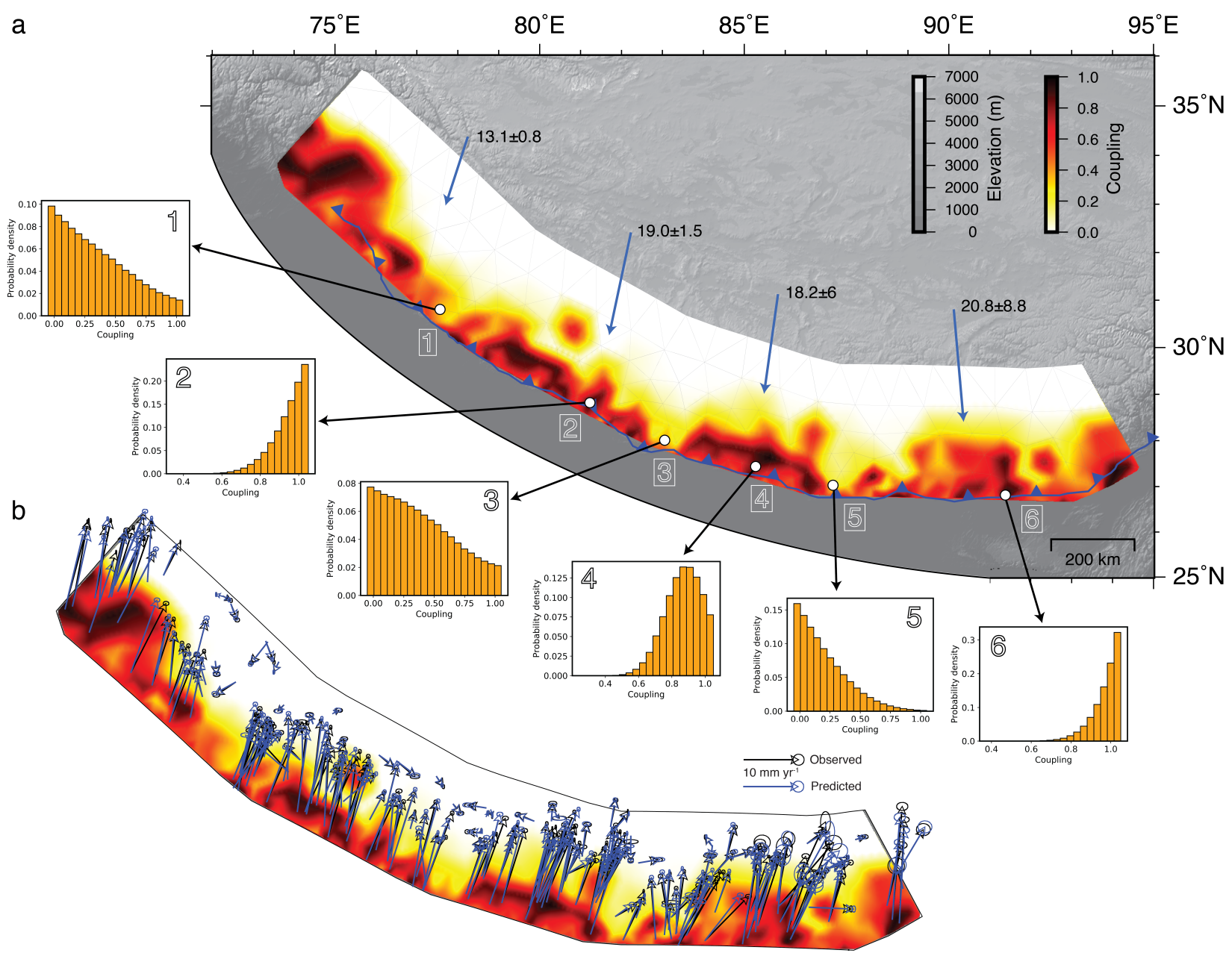

Figure 2. Posterior mean coupling model of the Himalayan megathrust. (a) The resulting posterior mean model accounts for data uncertainties and $10 \%$ of prediction uncertainties (see Methods for details). Coupling values are inverted at each triangle knot. For each of the histograms, orange bars are the marginal probability densities at discrete nodes of the fault model. Thin grey lines represent the fault mesh. The large blue arrows show the long-term velocities in each region. Solid blue line shows the surface trace of the Main Frontal Thrust. (b) Same posterior mean model with the GPS displacement (in the fixed Eurasian reference frame) and model predictions plotted as black and blue arrows, respectively. 


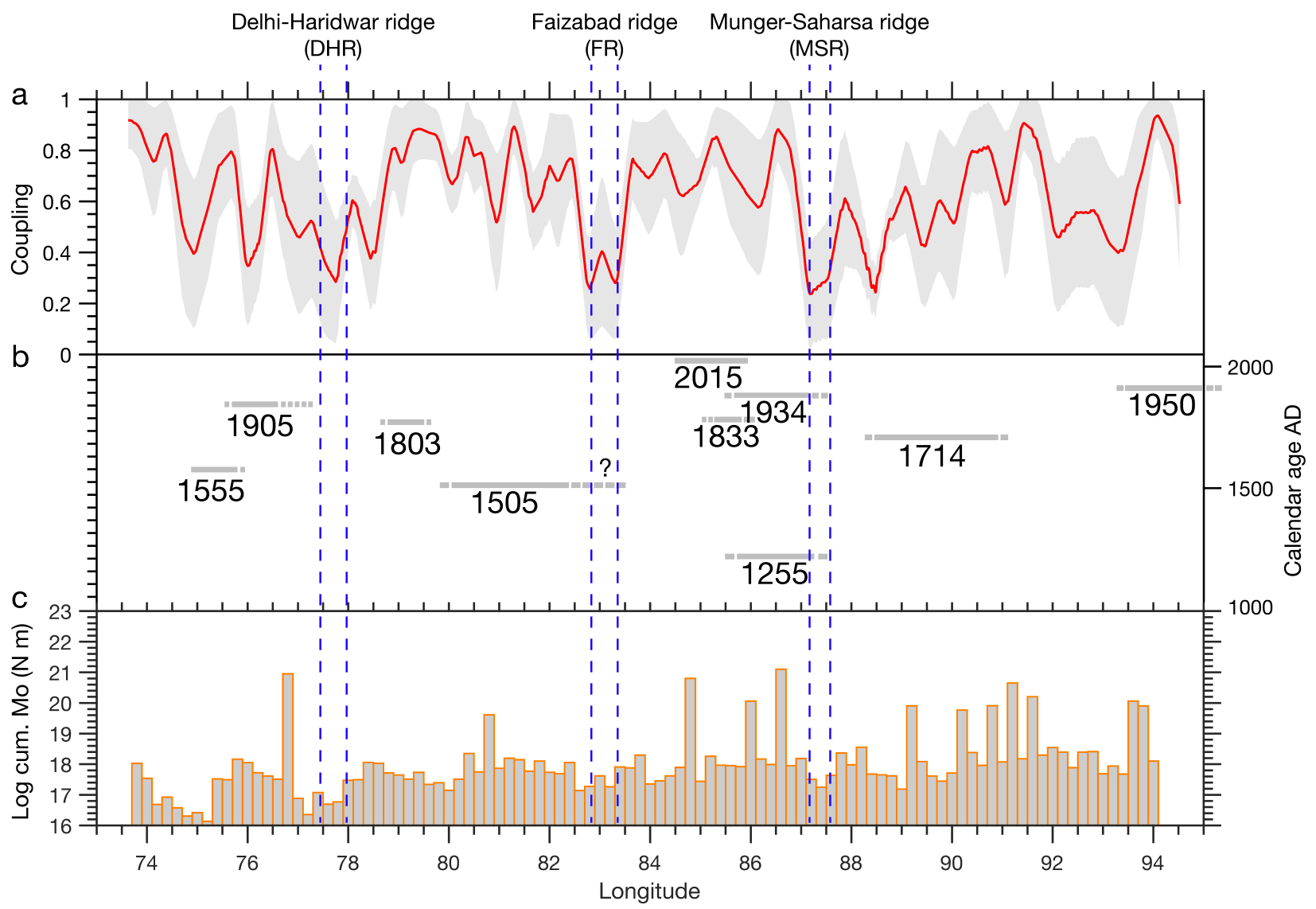

Figure 3. Comparison between along-strike variability of coupling, lateral extension of historical $M>7.5$ earthquakes, location of the subsurface ridges, and cumulative seismic moment released. (a) arc-parallel coupling profile at 45-50 $\mathrm{km}$ from the Main-Frontal-Thrust, derived from the posterior mean coupling model shown in Fig. 2. Shaded grey area represents the corresponding $2-\sigma$ deviation. Blue dashed lines indicate the location of the subsurface ridges in the Indo-Gangetic plains at the Main Frontal Thrust: DHR - Delhi Hardwar ridge; FR - Faizabad ridge; MSR - Munger-Saharsa ridge. (b) Known major and great earthquakes in the Himalaya (see Table S2). The lateral extension of the 1555, 1505, and 1255 earthquakes is speculative. (c) Lateral variation of cumulative seismic moment released of M>4.5 earthquakes across the Himalayan belt. The seismicity is defined within $250 \mathrm{~km}$ north of the Main Frontal Thrust. 
a

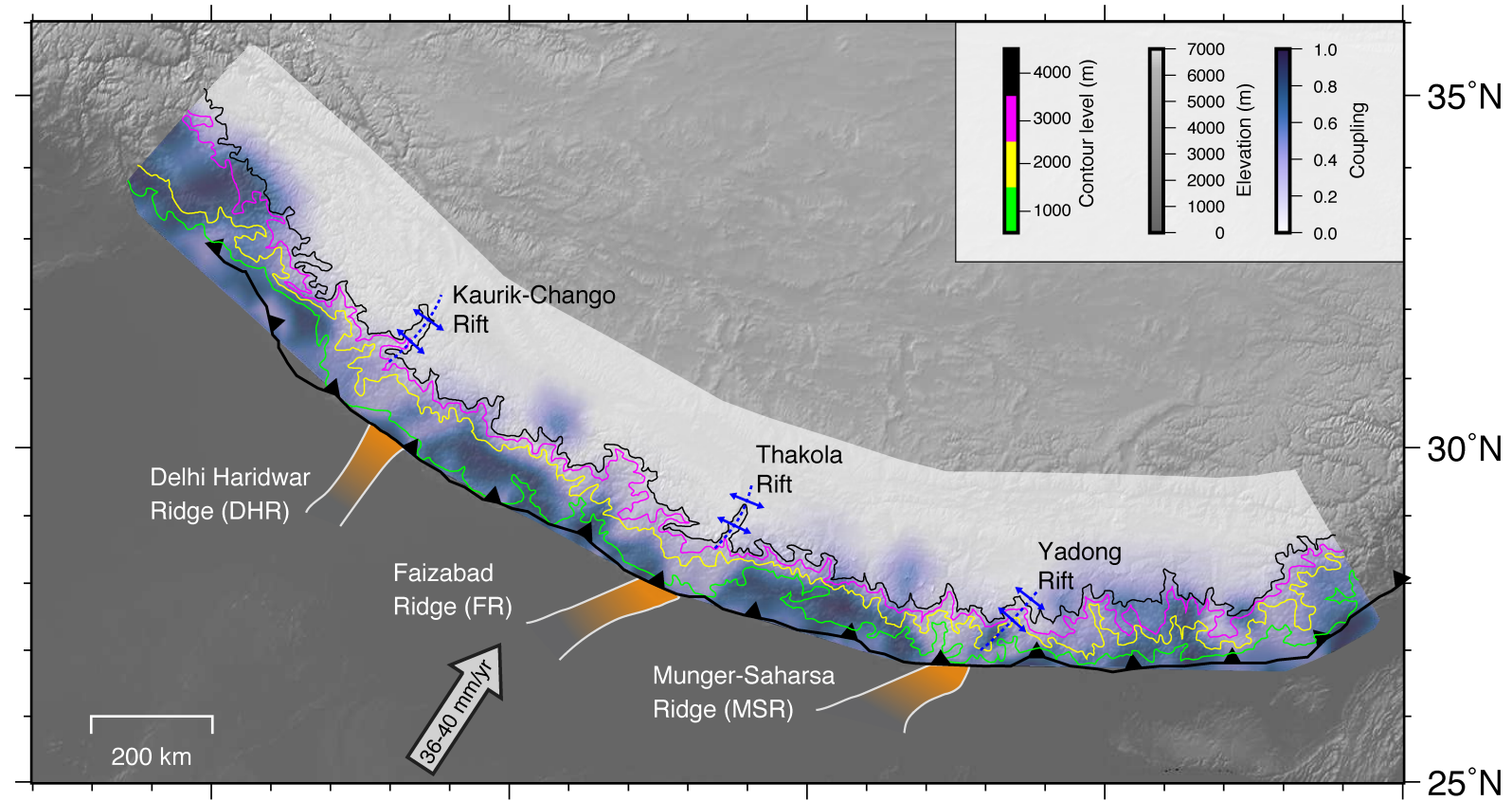

b

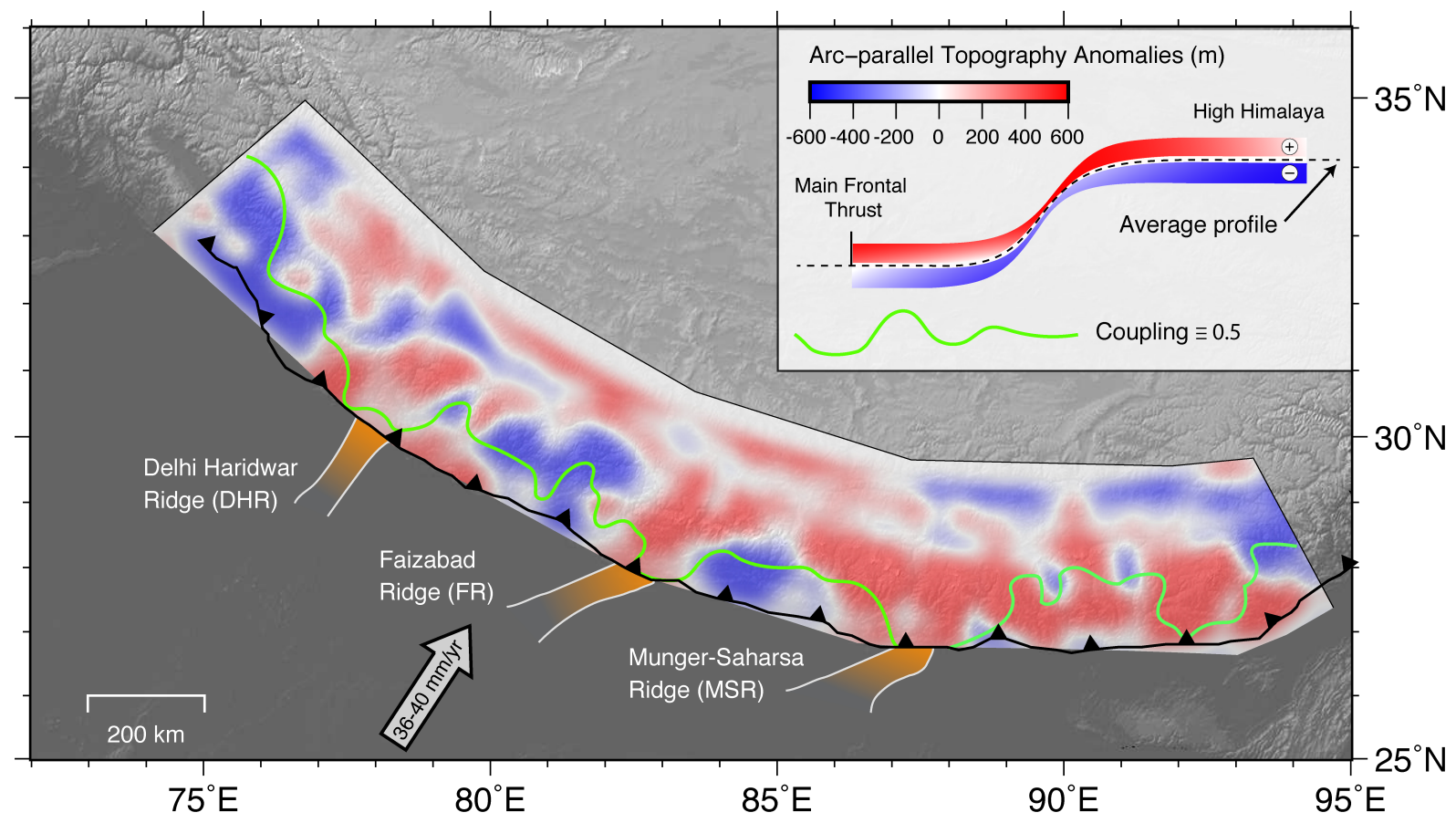

Figure 4. Interseismic coupling vs. topography. (a) Comparison between the presentday topography and coupling distribution inferred from the posterior mean coupling model shown in Fig. 2. Blue colormap displays the interseismic coupling pattern. Solid coloured lines show the topography contour lines. Dashed blue lines indicate the location of the Kaurik-Chango, Thakola, and Yadong rifts. (b) Arc-Parallel Topography Anomalies after smoothing with a 30-km radius circle Hetényi et al. (2016). Green line depicts the contour line of coupling $\equiv 0.5$. Orange patches indicate the location of the subsurface ridges beneath the Indo-Gangetic Plains. The Main Frontal Thrust fault is outlined in black. 